\title{
Biblioclastia en los siglos XX y XXI Revisión sistematizada
}

\section{( Cherie Flores-Fernández}

Universidad Tecnológica Metropolitana. Departamento Gestión de la Información. Chile I cflores@utem.cl /

https://orcid.org/oooo-0o01-5294-7157

\author{
Nicole Díaz-Sáez \\ Universidad Tecnológica Metropolitana. Escuela de Bibliotecología. Chile | nicole.diazs@utem.cl / \\ https://orcid.org/oooo-0002-4042-4276
}

\section{Andrea Gutiérrez-Navarrete}

Universidad Tecnológica Metropolitana. Escuela de Bibliotecología. Chile | andrea.gutierrezn@utem.cl /

https://orcid.org/oooo-0003-0694-60oo

\section{Fernando Henríquez-Fuentes}

Universidad Tecnológica Metropolitana. Escuela de Bibliotecología. Chile | fernando.henriquezf@utem.cl / https://orcid.org/oooo-0002-5048-626X

\section{Irene Reyes-Videla}

Universidad Tecnológica Metropolitana. Escuela de Bibliotecología. Chile | irene.reyesv@utem.cl /

https://orcid.org/oooo-0003-2654-6135

\begin{abstract}
Resumen
La biblioclastia es la destrucción de libros y material bibliográfico. El objetivo de esta investigación fue identificar los métodos y los contextos históricos de la destrucción intencional de libros en los siglos XX y XXl a través de una revisión sistematizada de la literatura. La búsqueda bibliográfica se realizó en: Scopus, Core, Google Scholar, Repositorios Latinoamericanos, Web of Science, Springer, Oxford, Unesco, E-lis, La
\end{abstract}

Palabras clave Biblioclastia Destrucción de libros Biblioclasmo Bibliocausto 


\title{
Biblioclasty in XX and XXI Centuries. Systematized Review
}

\begin{abstract}
Keywords

Biblioclasty Book destruction Biblioclasm Bibliocaust

Biblioclasty is the destruction of books and bibliographic material. The objective of this research was to identify the methods and historical contexts of the intentional destruction of books in the 20th and 21st centuries through a systematized literature review. A bibliographic search was conducted in the databases Scopus, Core, Google Scholar, Repositorios Latinoamericanos, Web of Science, Springer, Oxford, Unesco, E-lis, La Referencia, Jstor y Dialnet. 27 documents were selected for analysis, from which two contexts were established in which biblioclasty occurs: Conflict and Nonconflict. In addition, three techniques with which books are destroyed were identified: Burning, Manual Destruction, and Shredding. It is concluded that in the conflict context, the main cause of biblioclasty is censorship because of what the book represents as a means of freedom of expression. In the non-conflict context the destruction is for artistic reasons, vandalism or for health security. The most used method is book burning, related to conflict and security contexts (pandemic). Other methods were used to a lesser extent such as crushing.
\end{abstract}

Artículo recibido: 26-02-2021. Aceptado: 26-05-2021

\section{Introducción}

La historia de la destrucción de los libros se remonta a la antigüedad. Desde la fragmentación de las tablillas de la biblioteca del rey Asurbanipal en Nínive en manos de los babilonios en el 612 a. C.; la quema de libros en la China de Qin Shi Huang, quien obsesionado con la idea de borrar la historia pasada e instaurar su propio gobierno, promulgó como medida quemar todos los libros del archivo Zhou, iniciando además una persecución contra los intelectuales de las llamadas Cien Escuelas de Pensamiento; o los varios incendios sufridos por la Biblioteca de Alejandría, que solo en el primero perdió aproximadamente cuarenta mil rollos escritos, la destrucción de libros ha sido un asunto recurrente a lo largo de la historia, especialmente en contextos de conflicto político. Esto, porque el libro ha sido valorado "como un objeto que podría provocar un cambio social importante, un elemento peligroso como un arma" que ha hecho temer a reyes, dictadores e intelectuales a través del tiempo (Mardones Leiva y de Armas Pedraza, 2020: 181).

En relación con las amenazas que enfrentan los libros, Paul Valéry (en Ortega, 1979) sostiene que estos tienen los mismos enemigos que los hombres: la humedad, los animales, el tiempo y el propio contenido, además del fuego.

Así, entre una multiplicidad de factores relacionados con la destrucción de libros, surge el término biblioclastia.

\section{Concepto de biblioclastia}

Solari y Gómez (2008) en su libro Biblioclastia: los robos, la represión y sus resistencias en bibliotecas, archivos y museos de Latinoamérica señalan que la palabra biblioclastia no aparece en el diccionario de la Real Academia, sin embargo, puede entenderse como cualquier tipo de destrucción de libros. Esto teniendo en cuenta que biblioclastia deriva de la raíz de gr. $\beta\llcorner\beta \lambda$ i ov (rollo, libro), y el sufijo de gr. $k \lambda \alpha \sigma \mu o ́ s$ (romper), resultando literalmente en "romper libros" (Steinfeld, 2017). 
A pesar de no contar con un espacio en el diccionario de la RAE, el concepto biblioclastia ha sido definido por diversos autores.

Según lo registrado en el Diccionario de bibliología y ciencias afines, de José Martínez de Sousa, biblioclastia significa "Destrucción de libros...que puede ser de dos clases: natural, por un lado, o bien provocada intencionalmente por el hombre" (1993: 60). Por otra parte, en el Diccionario del archivero-bibliotecario el concepto es descrito como "rompimiento o destrucción de libros" (García, 2000: 43).

Bosch y Carsen, la definen como:

Conductas, prácticas, procedimientos, dispositivos y políticas que conducen a la destrucción, desvalorización o invisibilización de recursos de información y conocimiento, de los espacios físicos donde se alojan y circulan, y que atentan contra las personas que se relacionan tanto con esos recursos como con esos espacios físicos. Así como las conductas, prácticas, procedimientos, dispositivos y políticas que vulneran los derechos asociados a la información y el conocimiento (Bosch y Carsen, 2015: 7).

Por su parte, Bossié señala que la biblioclastia fue definida como la compulsión humana por destruir libros, y agrega que, desde los inicios de la civilización, los hombres han buscado la forma de imponer sus ideas por sobre otras, por lo que los libros "han sido objeto de esa pulsión biblioclástica durante toda la historia de la humanidad" (Bossié, 2008: 1).

Umberto Eco, en su artículo 'Desear, poseer y enloquecer', plantea que existen tres formas de biblioclastia, según las motivaciones que subyacen a esta: la biblioclastia fundamentalista, la biblioclastia por incuria y la biblioclastia por interés.

El biblioclasta fundamentalista no odia los libros como objeto, teme por su contenido y no quiere que otros los lean. [...] La biblioclastia por incuria es la de tantas bibliotecas italianas, tan pobres y tan poco cuidadas, que a menudo se transforman en espacios de destrucción del libro, porque una manera de destruir los libros consiste en dejarlos morir y hacerlos desaparecer en lugares recónditos e inaccesibles. El biblioclasta por interés destruye los libros para venderlos por partes, pues así obtiene mayor provecho (Eco, 2001: 57).

La destrucción voluntaria de los libros es mayor que aquella accidental. Según Báez (2005) un sesenta por ciento corresponde a la primera, causada por el hombre con fines específicos, y un cuarenta a la segunda, que tiene orígenes diversos, entre ellos accidentes, desastres naturales, extinción de una lengua entre otros.

Lamentablemente esta eliminación deliberada de los libros no solo forma parte de la historia antigua de la humanidad, sino que sigue siendo una práctica que es posible ver en nuestros días. En los siglos XX y XXI, durante períodos de revueltas sociales, nacionalistas y revolucionarios se apoderan del poder, consolidan su control e imponen ideologías estatales. En su libro Libricide: The Regime-sponsored Destruction of Books and Libraries in the Twentieth Century, Rebecca Knuth señala que, "para los extremistas, los libros y las bibliotecas son peligrosos tanto como personificación material de enemigos específicos como símbolos de fuerzas antitéticas más amplias: la expansión del cosmopolitismo, la democracia, el humanismo, el internacionalismo y el proceso de secularización" (Knuth, 2003: 247).

Debido a que la biblioclastia continúa estando presente en la época actual, se considera necesaria una investigación sistematizada del tema que pueda actualizar el estado de la biblioclastia en un período reciente, sobre todo pensando en que los sucesos ocurridos durante los últimos años tienen consecuencias aún visibles en nuestros días. 
Por lo anteriormente expuesto, el objetivo de la presente investigación fue identificar los métodos y los contextos históricos de la destrucción de libros en los siglos XX y XXI a través de una revisión sistematizada de literatura.

\section{Métodos}

Se realizó una revisión de la literatura con el fin de identificar los contextos y técnicas de la biblioclastia o destrucción de libros. La búsqueda bibliográfica se llevó a cabo en las siguientes bases de datos, las cuales fueron escogidas por ser multidisciplinaria y contar con acceso: Scopus, Core, Google Scholar, Repositorios Latinoamericanos, Web of Science, Springer, Oxford, Unesco, E-lis, La Referencia, Jstor, Dialnet.

Para la búsqueda de información se escogieron las palabras clave: Biblioclastia, Destrucción de libros, Biblioclasmo y Bibliocausto, con sus equivalentes en idioma inglés: Biblioclasty, Book destruction, Biblioclasm y Biblioclast. Las estrategias de búsqueda construidas fueron dos:

Biblioclastia OR "Destrucción de libros" OR Bibliocidio OR Bibliocausto Biblioclasty OR "Book destruction" OR Biblioclasm OR Biblioclast

La primera búsqueda, dio como resultado 2563 documentos recuperados. Respecto de los criterios de inclusión y exclusión, en primer lugar, se decidió considerar únicamente los documentos escritos en inglés o en español ( $\mathrm{n}=1820)$, de forma que del total de resultados iniciales se excluyeron 743 registros. Para esta fase se utilizaron los filtros por idioma de cada una de las bases de datos.

En la siguiente fase se utilizó el criterio de exclusión / inclusión por tipo de documento, incluyendo solamente artículos originales y tesis. De esta manera se excluyeron 169 documentos, resultando en un total de 1.651 documentos. Se utilizaron los filtros por tipo de documento con los que cuenta cada base de datos o en su defecto se realizó una revisión manual para la selección de documentos de acuerdo con este criterio.

Posteriormente, bajo el criterio de exclusión por nivel de accesibilidad, se descartaron los documentos que no permitían acceso al texto completo $(\mathrm{n}=30)$, disminuyendo el total a 1.651 .

En la fase siguiente se utilizaron criterios de inclusión y exclusión relacionados con el contenido. En el primer caso, se incluyeron aquellos documentos que abordaban el tema del contexto y/o técnicas de la destrucción de libros durante los siglos XX y XXI. En consecuencia, se excluyeron aquellos documentos que no trataran sobre los contextos y/o técnicas de la destrucción de libros durante los siglos XX y XXI. Esta selección se realizó mediante la lectura de los títulos y abstract de cada uno de los documentos, lo que arrojó un total de 1.514 registros, identificándose 107 documentos que cumplían con el criterio de inclusión mencionado. De ellos, 27 fueron eliminados por duplicidad, restando 80 registros.

Finalmente, se procedió a la lectura completa de los documentos, de los cuales 53 fueron descartados por no ajustarse a los criterios de inclusión y exclusión temáticos mencionados anteriormente. Esto permitió obtener un total de 27 documentos relevantes para la investigación.

El proceso de búsqueda, revisión y selección bibliográfica se muestra en el flujograma de la Figura 1. 
Total de documentos recuperados al aplicar las estrategias de búsqueda en las doce bases de datos

$$
(n=2563)
$$

Registros excluidos

$(n=743)$

Otros idiomas español e inglés

$(n=1820)$

$\downarrow$

Selección con base en el tipo de documento, artículos originales y tesis

$(n=1651)$

Registros excluidos

$(n=169)$

Otro tipo de documento texto completo

$$
(n=1621)
$$

Registros excluidos

$(n=30)$

Sin acceso a texto completo

$$
\downarrow
$$

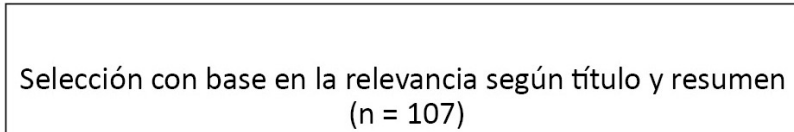

Registros excluidos

$(n=1514)$

No relevantes

$\downarrow$

Selección de documentos no duplicados a texto completo, evaluados para elegibilidad $(n=80)$

$\downarrow$

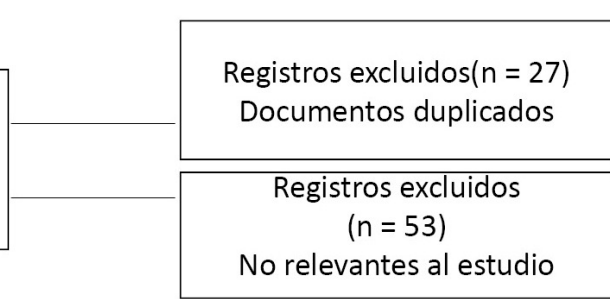

Documentos incluidos en la investigación $(n=27)$

Figura 1. Flujograma de selección de documentos.

\section{Resultados}

La revisión y el análisis de la bibliografía especializada realizada en este estudio, permitió identificar cinco contextos en los que se produce la destrucción de libros, los 
cuales se pueden clasificar en dos grandes grupos según las circunstancias: Conflictos -luchas ideológicas que derivan en enfrentamientos y ataques armados a nivel territorial en los que se ven perjudicados acervos de libros- y No conflictos - situaciones en las que no existen enfrentamientos y ataques armados a nivel territorial, en las que los libros son afectados por otras causas.

En la Tabla 1 se observan las categorías en que se presenta la biblioclastia, el contexto y el hecho histórico referido en la literatura.

Tabla 1. Categorías y contextos de biblioclastia en los siglos XX y XXI

\begin{tabular}{|c|c|c|}
\hline Categoría & Contexto & Hecho histórico \\
\hline \multirow[t]{2}{*}{ Conflictos } & Guerras & $\begin{array}{l}\text { Guerra Civil Española } \\
\text { Segunda Guerra Mundial } \\
\text { Guerra de los Balcanes } \\
\text { Guerra en Medio Oriente (Irak) }\end{array}$ \\
\hline & Dictaduras & $\begin{array}{l}\text { Dictadura en Chile } \\
\text { Dictadura en la Argentina } \\
\text { Dictadura en Uruguay } \\
\text { Dictadura en España } \\
\text { Dictadura en Honduras }\end{array}$ \\
\hline \multirow[t]{3}{*}{ No conflictos } & Pandemias & $\begin{array}{l}\text { Destrucción de libros por motivos sanitarios en } \\
\text { lowa siglo XX. }\end{array}$ \\
\hline & Arte & $\begin{array}{l}\text { Destrucción de libros como parte de } \\
\text { intervenciones artísticas o como obra en sí } \\
\text { misma. }\end{array}$ \\
\hline & Vandalismo & Destrucción de libros de forma particular \\
\hline
\end{tabular}

Por otro lado, fue posible reconocer tres técnicas con las que se destruyen los libros:

1. Otros métodos de destrucción de libros no fueron incluidos en la tabla de resultados por ser considerados como involuntarios o como consecuencia de otra acción:

a. Entierro: libros enterrados en terrenos descampados con el fin de protegerlos. b. Destrucción con agua: daño colateral en la extinción de incendios en bibliotecas.
»Quema: hacer que los libros sean consumidos por el fuego.

"Destrucción manual: individual o masiva, ejecutada con las manos.

» Trituración: reducir los libros, utilizando herramientas, como la guillotina.

\section{Discusión}

El análisis de los artículos seleccionados en la presente revisión demuestra que existen diversos contextos en los cuales se ejecutaron acciones biblioclásticas durante los dos últimos siglos.

En primer lugar, en la categoría Conflictos -definida como discrepancias ideológicas que derivan en enfrentamientos y ataques armados a nivel territorial en los que se ven perjudicados libros- se observa un eje temático entre los autores que abordan el tema: la censura como motivo principal de la destrucción de libros. Respecto a esto, Mardones Leiva (2015) señala la quema de libros de la editorial Quimantú como parte de la censura y la coartación de las libertades y derechos a la información perpetrada por la dictadura militar en Chile. Por otro lado, autores como Quevedo, Manzano y Vargas (2012), Meneses-Tello y Licea de Arenas (2005) y Vinelli (2020) plantean la intención de la dictadura argentina de instalar una nueva subjetividad en la sociedad a través de la destrucción de ciertos libros, debido al problema que significaban estos 
para sus fines.Otros autores se refieren al mismo tema en España donde a través de la represión cultural, el franquismo buscaba "limpiar y purificar el país de las ideas subversivas que habían adulterado las esencias españolas. Se trataba de suprimir el pensamiento de los vencidos e imponer el de los vencedores" (Martínez Rus, 2017: 178); en Honduras "los responsables del golpe de Estado comenzaron a perturbar y a dañar la estructura bibliográfica, bibliotecaria y documental de ese país" (MenesesTello, 2011: 220).

En la categoría Conflictos, se aprecian dos contextos donde se llevaron a cabo acciones de biblioclastia: las guerras y las dictaduras, y la literatura aborda la destrucción sistematizada de libros en aquellas circunstancias. Guevara y Molfino (2005), Agesta (2018.), Quevedo, Manzano y Vargas (2012) y Bonora (2016) coinciden en sus apreciaciones sobre la denominada "operación claridad", en la que la dictadura militar argentina modificó el aparato legal del estado para legitimar las persecuciones a ciertos libros y su posterior eliminación. "La represión hacia los libros, los escritores y los lectores fue en algunos casos ordenada, legalizada y sistemática” (Bossié, 2008: 26). Si bien la gran parte de estas acciones se llevaron a cabo mediante la quema, Canedo (2016) y Costa, Bossié y Purvis (2010) mencionan que existieron además casos de destrucción manual en masa de material bibliográfico en ciertas librerías perseguidas por el régimen militar. Según Vinelli (2020) también se suma la destrucción mediante quemas de libros por parte de personas que buscaban autocensurar su ideología por miedo a ser perseguidas o por pensar que al tener este material en sus casas ponían en riesgo a sus familias.

En España, en los años posteriores a la Guerra Civil, se dio un fenómeno similar, sobre todo una vez instaurado el régimen franquista, que con su motivación de censurar todo lo que fuera considerado como "anti-España" (Martínez Rus, 2017) modificó leyes y emitió decretos que legalizaban las destrucciones de libros. La misma autora menciona que se persiguió no solo a los libros, sino también a los autores y bibliotecarios, que tuvieron un destino similar.

Según Dreimane (2018) en la Alemania Nazi también hubo una situación de destrucción sistematizada. La ocupación nazi en Letonia respondía a los fines expansionistas de dicho país, y como tal, un aspecto importante que se debía atacar fue la cultura de la sociedad principalmente judía. El autor plantea que los germánicos efectuaron una destrucción sistematizada especialmente meticulosa, no destruyendo en masa todo lo que encontraran, sino de manera selectiva, con el fin de no perder información valiosa que les permitiera entender la sociedad letona y de esa forma ocupar esta información para sus fines. Por otro lado, Geuther (2010) plantea una destrucción menos parcializada por parte de los nazis. Si bien no se refiere específicamente a Letonia, menciona que fue el pueblo judío quien sería víctima de una destrucción masiva y sin ningún tipo de filtro.

Respecto a esto cabe mencionar que Bossié (2009) atribuye la diferencia entre hablar de sistematicidad o no sistematicidad en la destrucción de libros en dictaduras a la periodicidad de los estudios; mientras hace menos tiempo haya terminado el régimen será más difícil que la literatura hable de una sistematicidad por una herencia propia de la censura de los años previos.

En cuanto a las técnicas biblioclásticas utilizadas en la categoría Conflictos, la literatura demostró que se utilizó: quema, destrucción manual y trituración; siendo la quema la técnica más referenciada por los autores. De acuerdo con Jafarov (2019), en Azerbaiyán la destrucción causada por los armenios va desde libros valiosos a bibliotecas completas. A través de la quema, se estima que en dos años ardieron 5 millones de ejemplares, mientras que el valor de los daños sería de 20 millones y 
815 mil dólares. Por otra parte, de acuerdo con Mardones Leiva (2017) y Geuther, (2010), en 1933 los nazis dieron la orden de quemar 30.000 libros de autores judíos en la Opernplatz. Mardones Leiva agrega que "en su centro, ardieron los libros de los científicos Albert Einstein, Sigmund Freud, los poetas Stefan Zweig, Bertolt Brecht, Ricarda Huch, de los políticos August Bebel, Edward Bernstein, entre otros" (Mardones Leiva, 2017: 79-80).

En la Argentina, durante la dictadura se ordenó quemar más de medio millón de libros del Centro Editor de América Latina. De acuerdo con Bossié (2008: 14), la "quema estuvo a cargo del personal policial y lo paradójico es que en un intento de legalidad se elaboró el acta de la quema y un empleado de la editorial debió oficiar de fotógrafo oficial". Una situación similar ocurrió durante la dictadura en Chile, donde también a través de documentos oficiales se formalizó la quema de libros de la Universidad de Chile. "el Oficio 0160, Valparaíso 03 de marzo de 1975 , incluye una lista de 60 libros con la orden de ser quemados a la brevedad, de propiedad de la Universidad de Chile, Facultad de Arte y Tecnología, y de particulares" (Mardones Leiva y de Armas Pedraza, 2020: 177).

Algunos autores plantean una simbología existente en la quema del libro, entendiéndolo más allá del soporte en el cual se plasma un contenido. Mardones Leiva y de Armas Pedraza (2020), lo reconocen como un espacio de libertad e identidad. En el mismo sentido, Sánchez Herrador y Boza Puerta (2009) y Martínez Rus (2017) hacen hincapié en la violenta imagen que representa el fuego reduciendo a cenizas la pila de libros. "El fuego resultó más simbólico y efectivo en la eliminación de las ideas del enemigo...Con las teas incandescentes, toneladas de volúmenes fueron reducidos a cenizas, quedando solo el olor a papel y cartón quemado y el polvo de tanta infamia" (Martínez Rus, 2017: 178). De acuerdo con Martínez Valencia (2008), el fuego adquiere un simbolismo dual, por una parte representa lo negativo, aquello que debía ser eliminado; por otra parte es la purificación, la limpieza, lo nuevo.

Otra forma de destruir los libros fue la destrucción manual. "Romper manualmente todos los materiales, colocarlos en bolsas y luego tirar las mismas por cualquier calle de la ciudad" (Ratto, 2017: 99). Esta técnica es referenciada en textos relacionados con las dictaduras latinoamericanas. En Chile, los militares allanaron La Sebastiana, una de las casas del poeta Pablo Neruda, vaciaron la biblioteca, rompiendo y robando material (Mardones Leiva y de Armas Pedraza, 2020). En la Argentina, muchos de los libros del Centro Editor de América Latina fueron rotos y vendidos como papel, de acuerdo con lo dictaminado por la justicia (Guevara y Molfino, 2005).

Por otra parte, en cuanto a la técnica de trituración, en la España de Franco los libros fueron triturados con guillotinas para reutilizar las virutas del papel para nuevos ejemplares, "a fin de convertirlos en pasta de papel de los nuevos títulos imperiales y de mártires que se editaron durante la contienda y en la inmediata posguerra” (Martínez Rus, 2016: 178).

En lo que se refiere a otras técnicas de destrucción de libros, Mardones Leiva y de Armas Pedraza (2020) mencionan los entierros de estos por motivos de autocensura durante la dictadura en Chile; situación similar se da en otras dictaduras de Latinoamérica, como en la Argentina, donde los libros fueron enterrados en tambores o doblados y escondidos en muros ahuecados con el fin de protegerlos tanto a los documentos como a sus dueños (Tejero Yosovitch, Kaplan y Vilariño, 2020; Vinelli, 2020). Sin embargo, en este caso no fueron considerados como biblioclastia, puesto que la intención del entierro u ocultamiento 
no era destruirlos sino protegerlos, a pesar de que en la mayoría de los casos, no se logró recuperar el material.

Por otro lado, la literatura clasificada como No conflicto se divide en tres contextos: Arte, Pandemias y Vandalismo, siendo menor en relación con la categoría Conflicto y en su mayoría corresponden a casos particulares que aplican a una situación específica.

El primer contexto trata sobre la destrucción de libros por motivos artísticos, ya sean simbólicos o estéticos. Dentro de los documentos recuperados, solo uno menciona este tema, indicando que el método más utilizado es la destrucción manual. Vella (2006) explica que consiste en un proceso artístico en donde el libro es manipulado y "esculpido"; por lo tanto para el autor, esta biblioclastia artística no se considera lo mismo que la biblioclastia en sí, ya que esta práctica se refiere a una "metamorfosis del libro", que es entendida como un acto de resistencia con implicaciones político-filosóficas.

Además de la destrucción manual de los libros en el contexto artístico, también se documentan otras técnicas como la quema o la masticación (Lippard en Vella, 2006). Existieron diversas instancias en la que se presentó la destrucción de los libros como arte, principalmente en Europa, tales como la exposición de arte contemporáneo Documenta 6 en Kassel, Alemania en 1977, que exhibía la metamorfosis del libro, con trabajos de artistas como George Brecht, Dieter Roth o Lawrence Weiner.

Por otro lado, los libros también son destruidos para formar parte de esculturas y utilizados como atuendos para la realización de "performance", lo que tendría un fin estético o de representar la destrucción de libros como arte, placer y perversión.

En cuanto al contexto de pandemias, este se refiere a situaciones relacionadas con brotes de una enfermedad epidémica, extendida a un número importante de personas de un país o región. Un ejemplo de ello es el brote de Influenza española que azotó Estados Unidos en 2018. Skinner (2012) sostiene que en la ciudad de Iowa la propagación del virus ocasionó graves pérdidas en las colecciones de las bibliotecas que se mantuvieron abiertas a pesar de la crisis sanitaria. Agrega además, que el desconocimiento respecto al contagio y transmisión de la enfermedad, provocó que las autoridades sanitarias de la época tomaran medidas como la destrucción de libros a través de la quema.

Una de las bibliotecas afectadas fue la Carnegie-Stout Public Library, la cual solicitó a sus usuarios devolver los libros posiblemente contaminados para su quema mediante un comunicado: "Los libros utilizados por personas afectadas por enfermedades contagiosas o expuestos en locales en cuarentena por enfermedades contagiosas, serán devueltos a la Biblioteca para su destrucción" (Skinner, 2012: 51).

Si bien la destrucción de libros a través del fuego es una cuestión ampliamente mencionada anteriormente, en su mayoría por conflictos ideológicos, en este caso, la utilización del fuego tiene fines de carácter sanitario.

El vandalismo es otro de los contextos para la biblioclastia en la categoría No conflictos. Aparece mencionada en la bibliografía recuperada, aunque en menor medida. Thompson (1985) menciona el caso de Kjell Ludvik Kvavik, un alto funcionario noruego, quien destruía libros arrancando algunas de sus valiosas páginas con el fin de robarlas. El hecho ocurrió en una biblioteca universitaria en Oslo, desde donde Kvavik robaba mapas de libros raros y valiosos. Cuando la policía registró su casa, encontró más de cuatrocientos mapas extraídos de los libros. La técnica utilizada fue la destrucción manual. 


\section{Conclusión}

En la presente investigación sobre la biblioclastia en los siglos XX y XXI, se pueden distinguir dos grandes líneas en cuanto a los contextos en que esta se llevó a cabo; por una parte, se encuentran aquellos denominados Conflictos, y por el otro los No conflictos.

Respecto a la categoría Conflictos podemos apreciar que allí se concentra la mayor cantidad de destrucción de libros, principalmente debido a las guerras en Europa y Medio Oriente, así como por las múltiples dictaduras en América Latina.

En este contexto se hace patente el afán de censura por parte de las instituciones gubernamentales y militares, hacia los libros y contenido escrito en general, que no fueran consecuentes a sus ideologías. Se debe comprender que esta destrucción no persigue al libro como tal - como elemento donde se escriben contenidos - sino que lo que realmente alarmaba a los perpetradores de la biblioclastia eran las ideas filosóficas y políticas que estos libros contenían y la facilidad con la que se podían transmitir; por lo tanto, como lo señalan Invernizzi y Gociol (2002), lo que se proponían era la desaparición sistemática de símbolos, discursos, imágenes y tradiciones. Por tanto, es aquí donde el libro se debe pensar como un espacio de libertad y de expresión y no como "contenedor".

Siguiendo la misma línea, específicamente en relación con las dictaduras, se puede dimensionar el peligro que representaban los libros para los intereses de los regímenes con la creación de planes y cuerpos legales especialmente detallados y meticulosos destinados exclusivamente a perseguir, encontrar y finalmente poder destruir todas aquellas obras que contuviera mensajes contrarios a los gobernantes y sus ideologías.

En cuanto a la categoría No conflictos, es posible apreciar que la cantidad de material destruido es considerablemente menor a la observada en los contextos anteriores. Por un lado, la destrucción debido a pandemias en el siglo XX sufrió una importante disminución, a consecuencia del aumento de la información respecto al comportamiento de los virus y bacterias, por lo que este tipo de eliminación de libros es inversamente proporcional a los avances en materia de medicina y sanidad.

Por otra parte, el contexto de arte muestra muchas veces un daño intencional, pero controlado, distinguiéndose casos puntuales en la literatura. Para este tipo de destrucción, se ha propuesto el término biblioclasma artístico, siendo considerado un fenómeno de arte posmoderno (Vella, 2006).

El método de destrucción de libros más recurrente fue la quema, en su mayoría de títulos prohibidos los cuales estaban relacionados con los conflictos anteriormente mencionados. La intención de quemar el libro era no dejar ningún rastro de su contenido, se mezclaban las cenizas con la tierra, e incluso se quemaban bibliotecas completas.

También hubo otros métodos menos comunes, a los libros se les trituraba, guillotinaba, se desmembraban a través del robo de páginas, y también se destruyeron muchos libros masivamente de forma manual y agresiva; estos métodos no eran tan comunes debido a que no resultaban tan eficientes y había una posible recuperación del material.

Durante la revisión se observó que varios métodos de destrucción coinciden con los contextos, ya sea Conflicto o No conflicto; por ejemplo, la quema, prohibición y eliminación de ciertos títulos durante las dictaduras latinoamericanas de la segunda mitad del siglo XX, fueron métodos que también se utilizaron durante las guerras. A esta última también se le asocian las formas de destrucción como guillotinar y triturar libros que, si bien fueron menos comunes, tienen mucha relación con el contexto que se vivió durante estos conflictos en donde se coartaba la libertad de expresión. Pasando a los No conflictos, en 
la biblioclastia artística también se ha utilizado la quema, para plantear una metamorfosis del libro, además de otro tipo de destrucciones manuales. Esta actividad de biblioclastia artística generaba placer a las personas que la ejecutaban, basado en el disfrute del vandalismo contra los libros.

La investigación presentada demuestra que no es necesario remontarse a tiempos antiguos para encontrar ejemplos de destrucción masiva, sistemática y premeditada de libros, porque "de la maldad pura a la inconsciencia organizada pasando por la más absoluta ignorancia, veremos, siglo tras siglo, el variado rostro de la barbarie, con el riesgo de comprobar que se encuentra demasiado cerca del nuestro" (Polastron, 2014: 4). Lamentablemente la biblioclastia sigue ocurriendo en la actualidad, en un intento de eliminar la memoria, lo cual es un fenómeno de preocupación y alarma, puesto que este daño al patrimonio cultural deja a la humanidad sin memoria escrita, sin sentido para su presente y sin base para la construcción de su futuro. 


\section{Q Referencias bibliográficas}

Agesta, Daiana. 2018. Operación claridad, o de cómo tapar el sol con una mano. Represiones culturales en la Universidad Nacional del Sur. <https://bit. ly/3h4F886> [Consulta: 29 octubre 2020].

»Báez, Fernando. 2005. Historia universal de la destrucción de los libros. De las tablillas sumerias a la guerra de Irak. Buenos Aires: Sudamericana.

"Bonora, Elena. 2016. Libros prohibidos en la Biblioteca del Instituto de Estudios del Tercer Mundo Eva Perón. Biblioteca Arturo Marasso. Departamento de Humanidades. UNS <https://bit.ly/3mG96k1> [Consulta: 23 octubre 2020].

»Bosch, Mela y Tatiana Carsen. 2015. Biblioclastia: terminología y definición de un concepto. En Foro de Investigación Universitaria en Museología, Archivología y Bibliotecología. Facultad de Filosofía y Humanidades. Universidad Nacional de Córdoba. <https://bit.ly/34sj4yT> [Consulta: 23 octubre 2020].

»Bossié, Florencia. 2008. Biblioclastía y bibliotecología: recuerdos que resisten en la ciudad de La Plata. En Congreso Textos, autores y bibliotecas. (24 al 26 de septiembre de 2008: Córdoba). Trabajos presentados. Córdoba: Universidad Nacional de Córdoba. <http://www.memoria.fahce.unlp.edu.ar/trab_eventos/ ev.703/ev.703.pdf> [Consulta: 23 octubre 2020].

»Bossié, Florencia. 2009. Libros, bibliotecas y bibliotecarios. Una cuestión de memoria. En Información, cultura y sociedad. Vol. 20, 13-40. <http://revistascientificas.filo.uba.ar/index.php/ICS/article/view/804>[Consulta: 27 octubre 2020].

"Canedo, Emanuel. 2016. Tinta Prohibida. De Fahrenheit 451 a Argentina 1976: Análisis de los libros prohibidos por la dictadura militar argentina (1976-1983). Rosario: Universidad Nacional de Rosario. Facultad de Ciencia Política y Relaciones Internaciones. Escuela de Comunicación Social. Tesis de grado. <https:// bit.ly/3mvzs8c > [Consulta: 23 octubre 2020].

»Costa, María Eugenia, Bossié, Florencia y Purvis, Gabriela. 2010. Lecturas y censuras en la Argentina: enfoques historiográficos renovadores de la Historia del Libro. En Jornada de Intercambio y Reflexión acerca de la Investigación en Bibliotecología. (1ª: 6-7 de diciembre de 2010: La Plata). Trabajos presentados. La Plata: Universidad Nacional de La Plata. Facultad de Humanidades y Ciencias de la Educación. <https://bit.ly/3hdoMdr> [Consulta: 29 octubre 2020].

»Dreimane, Jana. 2018. The Paths of books of Latvian Jews during World War II. En Knygotyra. Vol.71, 210-235. <https://doi.org/10.15388/Knygotyra.2018.71.9>

„Eco, Umberto. 2001. Desear, poseer y enloquecer. En El malpensante. No. 31. $<$ https://www.elmalpensante.com/articulo/2480/desear_poseer_y_enloquecer> [Consulta: 29 octubre 2020].

" García, Luis. 2000. Diccionario del archivero-bibliotecario: terminología de la elaboración, tratamiento y utilización de los materiales propios de los centros documentales. Gijón: Trea.

"Geuther, Christina. 2010. Setting fire to the Square. Boston: Boston University School of Theology <https://bit.ly/38g40Wd > [Consulta: 27 octubre 2020].

»Guevara, Alfredo Antonio y María del Rosario Molfino. 2005. La censura y la destrucción de libros en el último gobierno de facto (1976-1983). En Jornadas 
de Sociología de la UNLP. (4⿳ạ: 23 al 25 de noviembre de 2005: La Plata). Trabajos presentados. La Plata: Universidad Nacional de La Plata. <https://bit. ly/3r7OyUO > [Consulta: 29 octubre 2020].

»Invernizzi, Hernán y Judith Gociol. 2002. Un golpe a los libros. Represión a la cultura durante la última dictadura militar. Buenos Aires: Eudeba.

" Jafarov, Javid. 2019. A brief history of Armenian biblioclasm. En Manuscripts don't burn. Vol. 1, no. 8, 93-100. <https://bit.ly/2WrVCNM> [Consulta: 27 octubre 2020].

»Knuth, Rebecca. 2003. Libricide: The Regime-Sponsored Destruction of Books and Libraries During the Twentieth Century. CT: Praeger.

" Mardones Leiva, Marjorie. 2015. Las manchas de la memoria: Editorial Quimantú y Editorial Gabriela Mistral. En Revista Faro. Vol. 1, no. 21, 72-8o. <https://bit. ly/3myvVWo> [Consulta: 23 octubre 2020].

»Mardones Leiva, Marjorie, coord. 2017. Biblioteca Recuperada: La batalla por la memoria. Valparaíso, 1973. Chile: Universidad de Playa Ancha. Ministerio de Educación. <https://bit.ly/3mw8AEX> [Consulta: 29 octubre 2020].

" Mardones Leiva, Marjorie y Tania de Armas Pedraza. 2020. La destrucción del libro en Valparaíso, 1973. En Investigación Bibliotecológica. Vol. 34, no. 84, 169183. <http://dx.doi.org/10.22201/iibi.24488321xe.2020.84.58178>

» Martínez de Sousa, José. 1993. Diccionario de bibliología y ciencias afines. Madrid: Fundación Germán Sánchez Ruipérez.

»Martínez Rus, Ana. 2016. De quemas y purgas. El bibliocausto franquista durante la Guerra Civil. En Bulletin hispanique. Vol. 118, no. 1, 177-194. <https://doi. org/10.400o/bulletinhispanique.4299>

» Martínez Rus, Ana. 2017. No sólo hubo censura: la destrucción y depuración de libros en España (1936-1948). En Creneida. Anuario De Literaturas Hispánicas. Vol. 5, 35-65. <https://doi.org/10.21071/calh.v5i.10368>

"Martínez Valencia, Marta. 2008. Setenta años después regresaban a la Biblioteca Nacional. En Biblioteca en guerra, dos años de exposición. Dossier. No. 163 , 86 - 88. <https://bit.ly/37uNEtQ $>$ [Consulta: 29 octubre 2020].

»Meneses-Tello, Felipe. 2011. Bibliotecas, información y golpe de estado: teoría en el contexto relacionado con la crisis política en Honduras. En Revista General de Información y Documentación. No.21, 187-224. <https://doi.org/10.5209/ rev_RGID.2011.v21.37429>

»Meneses-Tello, Felipe y Judith Licea de Arenas. 2005. El problema ideológico de la selección-eliminación-destrucción de libros y bibliotecas. En Ciencias de la Información. Vol.36, no. 2, 65-71. <https://bit.ly/3mzpWAl> [Consulta: 23 octubre 2020].

»Ortega, Julio. 1979. La escritura de la vanguardia. En Revista Iberoamericana. Vol. 45, no. 106-107. <https://doi.org/10.5195/reviberoamer.1979.3367 >

"Polastron, Lucien. 2014. Libros en llamas. Historia de la interminable destrucción de las bibliotecas. México: Fondo de Cultura Económica.

"Quevedo, Marcelo, Héctor Manzano y Miriam Vargas. 2012. Mendoza, bibliotecas y protagonistas: censura y memoria 1976-1983. Mendoza: Universidad Nacional de Cuyo. Tesis de licenciatura. <https://bit.ly/2]27qmW> [Consulta: 23 octubre 2020]. 
»Ratto, Claudio. 2017. Historias de autocensura, ocultamiento y biblioclastia ejercidas sobre las lecturas y los textos durante la última dictadura cívico - militar en la República Argentina (1976 - 1983). Buenos Aires: Universidad Nacional de Mar del Plata. Tesis de Licenciatura. <https://bit.ly/37xcxVL> [Consulta: 25 de octubre 2020].

»Sánchez Herrador, Miguel y Mariano Boza Puerta. 2009. Señales de humo. La destrucción bibliográfica durante la Guerra Civil. En AH Andalucía en la historia. Vol. 26, 68-72. <https://bit.ly/3akbhqO> [Consulta: 25 octubre 2020].

»Skinner, Julia. 2012. Returned, then Burnt: lowa Libraries, Contagion, and the 1918 Influenza Pandemic. En The Graduate History Review. Vol. 4, no.1. <https:// bit.ly/38fX308> [Consulta: 23 octubre 2020].

"Solari, Tomás y Jorge Gómez. 2008. Biblioclastia: los robos, la represión y sus resistencias en bibliotecas, archivos y museos de Latinoamérica. Buenos Aires: Eudeba.

"Steinfeld, Federico Guillermo. 2017. Identidad entre Subjetividad e Información en la Biblioclastia. Buenos Aires: Ministerio de Educación. Instituto de Formación Técnica Superior No. 13. Tesis de grado. <https://bit.ly/3p2Afiz> [Consulta: 25 octubre 2020].

» Tejero Yosovitch, Yael Natalia, Laura Sabino Kaplan y Andrea Vilariño. 2020. Configuraciones del Conurbano en los testimonios de ocultamiento y destrucción de libros durante la última dictadura militar. En Everba, revista de estudios de la cultura. Enero. <https://www.academia.edu/41875230/Configuraciones_del_ Conurbano_en_los_testimonios_de_ocultamiento_y_destrucci\% $3 \%$ B 3 _ de_libros_durante_la_\%C3\%BAltima_dictadura_militar> [Consulta: 27 octubre 2020].

"Thompson, Lawrence. 1985. Biblioclasm in Norway. En Library \& Archival Security. Vol. 6, no. 4, 13-16. <https://doi.org/10.1300//114v06no4_02>

"Vella, Raphael. 2006. The unpresentable: Artistic biblioclasm and the sublime. Londres: University of the Arts. 2006. Tesis de doctorado. <https://bit.ly/3nz1TDv> [Consulta: 23 octubre 2020].

»Vinelli, Elena. 2020. La lengua de los libros. En Everba, revista de estudios de la cultura. Enero 8o-87. 